\title{
Pembuatan dan Karakterisasi Magnet Bonded NdFeB dengan Teknik Green Compact
}

\author{
Tony Kristiantoro, ${ }^{*}$ Nanang Sudrajat, dan Widhya Budiawan \\ Pusat Penelitian Elektronika dan Telekomunikasi - LIPI \\ Jl. Cisitu 21/ 154D, Bandung 40135
}

\begin{abstract}
Intisari
Telah dilakukan penelitian proses pembuatan permanen magnet bonded $\mathrm{NdFeB}$ dengan menggunakan teknik green compact. Magnet bonded ini dibuat dengan menggunakan serbuk magnet NdFeB MQEP 16-7, serbuk magnet ini sudah memiliki komposisi serbuk NdFeB dan bindernya berupa epoxy resin, serbuk ini memiliki kelebihan yaitu tahan korosi. 10 gr serbuk MQEP dikompaksi dengan teknik green compact, kemudian dibakar untuk mendapatkan magnet bonded yang kuat dan kompak. Green compact dengan variasi kompaksi 25,35 dan $45 \mathrm{~kg} / \mathrm{cm}^{2}$, sedangkan temperatur divariasikan 150,175 dan $200^{\circ} \mathrm{C}$. Sampel hasil kompaksi dihitung densitas fisiknya, diukur rapat fluks magnetnya dengan menggunakan Gaussmeter Yokogawa dan dikarakteristik sifat magnetnya dengan Permagraph Magnet Physik Germany. Penelitian ini menghasilkan magnet bonded $\mathrm{NdFeB}$ terbaik pada perlakuan green compact dengan tekanan $25 \mathrm{~kg} / \mathrm{cm}^{2}$ dan temperatur burn compact $200^{\circ} \mathrm{C}$ yaitu dengan densitas fisik $4,74 \mathrm{gr} / \mathrm{cm} 3$ dan rapat fluks magnetik 2100 Gauss. Hasil karakterisasi menggunakan permagraph magnet physik diperoleh nilai induksi remanen $\left(\mathrm{B}_{r}\right)$ sebesar 5,8 kG, daya koersifitas $\left(\mathrm{H}_{c}\right)$ sebesar 6,618 kOe dan produk energi maksimum $\left(\mathrm{Bh}_{\max }\right)$ sebesar 4,56 MGOe.
\end{abstract}

\begin{abstract}
Research manufacture bonded NdFeB permanent magnets by using the techniques of green compact has been done. Bonded magnet is made by using powder MQEP NdFeB magnets, the magnetic powder was chosen because it is very appropriate for use in engineering green compact where it already has a composition MQEP $\mathrm{NdFeB}$ powder and epoxy resin as the binder, this powder has the advantages of corrosion-resistant so it is not easy oxidized. MQEP powder is then weighed using a balance digital much as 10 grams of each sample, then compacted by green compact techniques. Samples of compacted and then burned (burn compact) for bonded magnets are strong and compact (not brittle and easily broken). Green compact using a variation of compacting 25,35 and $45 \mathrm{~kg} / \mathrm{cm}^{2}$, while the temperature was varied between 150,175 and $200{ }^{\circ} \mathrm{C}$. Samples were then calculated density compaction results of his physical, tightly measured the magnetic flux by using Gauss Meter Yokogawa and magnetic properties were characterized using Magnet Physik Permagraph Germany. The study produced the best $\mathrm{NdFeB}$ bonded magnets in the treatment of green compact with a pressure of $25 \mathrm{~kg} / \mathrm{cm}^{2}$ and burn compact temperature $200^{\circ} \mathrm{C}$ is the physical density of $4.74 \mathrm{gr} / \mathrm{cm}^{3}$ obtained measurement results meeting for 2100 Gauss magnetic flux. The results of characterization using magnetic permagraph physik obtained values remanent induction $\left(\mathrm{B}_{r}\right)$ of $5.8 \mathrm{kG}$, the coercivity $\left(\mathrm{H}_{c}\right)$ of $6.618 \mathrm{KOe}$ and maximum energy product $\left(\mathrm{Bh}_{\max }\right)$ at 4,56 MGOe.
\end{abstract}

KATA KUNCI: magnet bonded, MQEP, green compact

\section{PENDAHULUAN}

Pada awalnya magnet terbuat dari baja keras dan berbagai alloy misal ALNICO dari paduan logam Al dan Ni, kemudian berkembang menjadi terbuat dari keramik atau ferit dari oksida-oksida logam misalnya feroxdure $\mathrm{SrFe}_{12} \mathrm{O}_{19}$ dan Barium Ferrrite $\mathrm{BrFe}_{12} \mathrm{O}_{19}$, magnet-magnet ini relatif memiliki energi produk yang rendah.

Magnet NdFeB adalah material magnet permanen generasi ketiga yang terbuat dari tanah jarang [1] memiliki energi produk yang besar, sudah menjadi bagian yang penting dalam

*E-MAIL: tony@ppet.lipi.go.id kehidupan sehari-hari manusia. Magnet NdFeB ini banyak diaplikasikan pada berbagai peralatan seperti motor listrik, speaker, CD player, oven microwave. Aplikasi lain dari komponen magnet juga banyak dijumpai pada peralatan intrumentasi, peralatan produksi dan pada laboratorium penelitian [2]. Akan tetapi kontribusi magnet sering diabaikan karena komponen ini sudah tertanam di dalam suatu perangkat dan tidak terlihat. Pada kenyataannya kebutuhan akan komponen ini menjadi sangat beragam tergantung kepada kegunaan dan fungsi suatu perangkat. Secara umum, kebutuhan akan komponen magnet dibedakan berdasarkan bentuk, dimensi dan kuat medannya.

$\mathrm{NdFeB}$ dikenal sebagai magnet tanah jarang karena komposisi materialnya tersusun dari unsur-unsur tanah jarang. NdFeB memiliki sifat korosif dan energi produk yang maksimum [3]. 


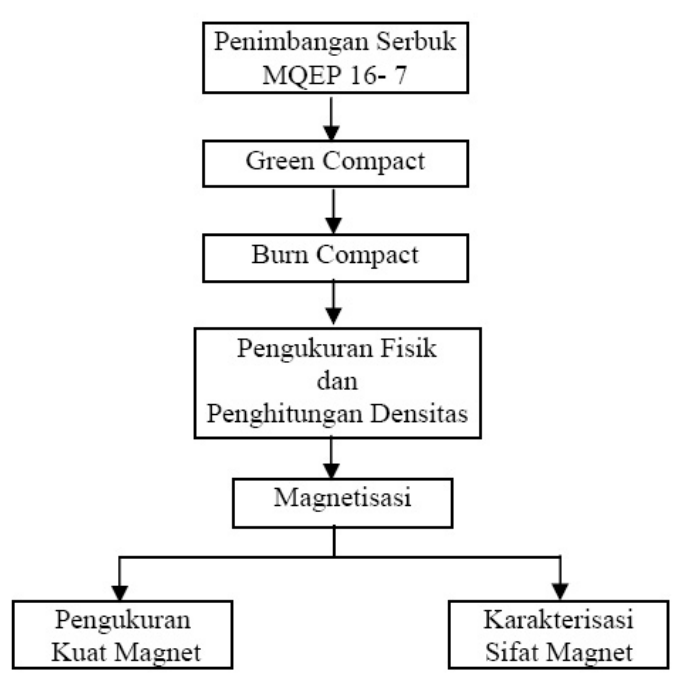

Gambar 1: Alur proses pembuatan magnet bonded

\section{METODOLOGI}

Proses pembuatan magnet bonded yang dilakukan menggunakan magnet serbuk NdFeB MQEP 16-7 produksi Magnequench. Serbuk magnet MQEP ditimbang seberat $10 \mathrm{gr}$ dikompaksi dengan menggunakan teknik green compact pada tekanan yang divariasikan. Sampel hasil kompaksi kemudian dibakar pada temperatur yang divariasikan. Selanjutnya sampel dimagnetisasi menggunakan Impulse Magnetizer lalu dikarakterisasi menggunakan permagraph untuk mengetahui sifat magnet dan diukur dengan Gaussmeter untuk mengetahui kuat medan magnet.

\section{EKSPERIMEN}

Serbuk magnet MQEP 16-7 produksi magnequench ini merupakan serbuk magnet crashed ribbon sehingga akan mengurangi korosi karena bersifat tahan akan oksidasi. Serbuk magnet ditimbang seberat 10 gr sebanyak 6 kali penimbangan untuk mempersiapkan 6 buah sampel. Alur proses pembuatan magnet bonded seperti pada Gambar 1 .

Serbuk magnet MQEP 16-7 yang sudah ditimbang dimasukan ke dalam dies casting yang berdiameter $20 \mathrm{~mm}$ selanjutnya dikompaksi menggunakan mesin press bertenaga hidrolik. Perlakuan kompaksi diberikan dengan variasi kompaksi yaitu antara $25 \mathrm{~kg} / \mathrm{cm}^{2}, 35 \mathrm{~kg} / \mathrm{cm}^{2}$ dan $45 \mathrm{~kg} / \mathrm{cm}^{2}$. Perlakuan ini diberikan untuk memastikan kepadatan struktur MQEP 16-7 terjadi secara optimal. Sampel hasil kompaksi kemudian dibakar menggunakan furnace dengan variasi temperatur antara $150^{\circ} \mathrm{C}, 175^{\circ} \mathrm{C}$ dan $200^{\circ} \mathrm{C}$. Hasil dari pembakaran ini diperoleh sampel magnet bonded yang siap untuk dimagnetisasi. Sebelum proses magnetisasi, dilakukan pengukuran dimensi fisik dan penghitungan densitasnya. Pengukuran dimensi fisik yaitu massa (gr), diameter ( $\mathrm{mm}$ ) dan tebal $(\mathrm{mm})$. Sampel kemudian dimagnetisasi menggunakan

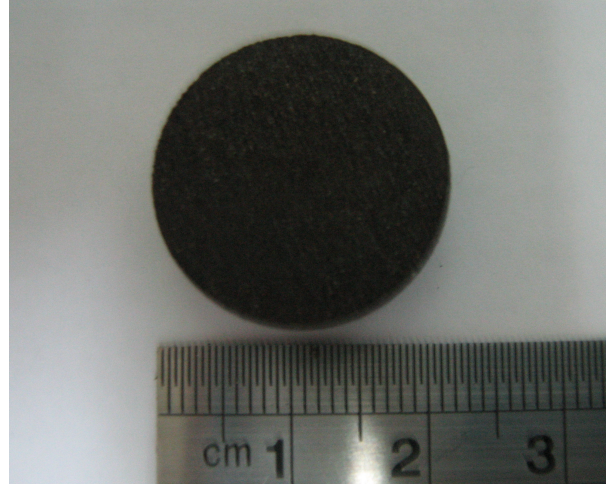

Gambar 2: Magnet bonded $\mathrm{NdFeB}$

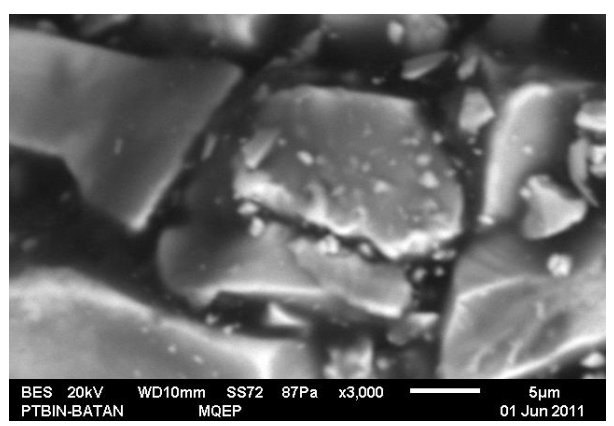

Gambar 3: Hasil SEM magnet bonded MQEP

impulse magnetisierer dengan memberikan energi maksimal 2400 volt secara kejut/ sesaat sehingga sampel mencapai titik jenuh (memiliki energi produk maksimum) dan dikarakterisasi untuk mendapatkan besaran-besaran induksi remanen $\left(\mathrm{B}_{r}\right) \mathrm{kG}$, koersifitas $\left(\mathrm{H}_{c} \mathrm{j}\right) \mathrm{kOe}$, produk energi maksimum $\left(\mathrm{Bh}_{\max }\right)$ MGOe. Langkah terakhir adalah dengan mengukur kuat medan magnet $\left(\mathrm{B}_{r}\right)$ menggunakan Gaussmeter.

\section{HASIL DAN PEMBAHASAN}

Dari eksperimen yang dilakukan telah diperoleh hasil sampel magnet bonded NdFeB. Gambar 2 memperlihatkan bentuk fisik magnet bonded $\mathrm{NdFeB}$ yang memiliki diameter $20 \mathrm{~mm}$ dengan ketebalan bervariasi antara 6,64 $\mathrm{mm}$ sampai dengan 7,37 mm.

Pada Gambar 3 terlihat serbuk MQP 16-7 yang sudah terikat oleh polimer, hal ini ditunjukan oleh rapatnya ikatan antar NdFeB. Pengukuran dimensi fisik sampel dilakukan untuk menghitung densitas magnet bonded. Dari eksperimen diperoleh densitas terbesar yaitu sebesar $4,74 \mathrm{gr} / \mathrm{cm}^{3}$. Hal ini seperti terlihat dari perbandingan pada Tabel I dan Tabel II.

Pada eksperimen ini dilakukan variasi temperatur burn compact, sedangkan kompaksi green compact diberikan tetap sebesar $25 \mathrm{~kg} / \mathrm{cm}^{2}$, tujuannya adalah agar diketahui temperatur efektif untuk burn compact. Nilai induksi remanen (residual flux density) $\mathrm{B}_{r}$ terbesar diperoleh saat temperatur burn compact $200{ }^{\circ} \mathrm{C}$ yaitu $5,28 \mathrm{kG}$ dan nilai kuat medan (rapat fluk) terbesar diperoleh 2100 Gauss. Semakin besar temper- 
TABEL I: Karakteristik variasi temperatur terhadap tekanan

\begin{tabular}{lccc}
\hline \hline Sifat & \multicolumn{3}{c}{ Temperatur $\left({ }^{\circ} \mathrm{C}\right)$} \\
Magnet & 150 & 175 & 200 \\
\hline & & & \\
$\mathrm{B}_{r}(\mathrm{kG})$ & 4,02 & 4,97 & 5,28 \\
$\mathrm{H}_{c}(\mathrm{kOe})$ & 6,068 & 6,647 & 6,618 \\
Bhmax $(\mathrm{MGOe})$ & 2,73 & 4,44 & 4,56 \\
Density $\left(\mathrm{g} / \mathrm{cm}^{3}\right)$ & 4,4 & 4,55 & 4,74 \\
Gauss & 1500 & 1600 & 2100 \\
\hline
\end{tabular}

TABEL II: Karakteristik variasi tekanan terhadap temperatur

\begin{tabular}{lccc}
\hline \hline Sifat & \multicolumn{3}{c}{ Temperatur $\left({ }^{\circ} \mathrm{C}\right)$} \\
Magnet & 150 & 175 & 200 \\
\hline & & & \\
$\mathrm{B}_{r}(\mathrm{kG})$ & 5,28 & 5,27 & 5,25 \\
$\mathrm{H}_{c}(\mathrm{kOe})$ & 6,618 & 6,402 & 6,213 \\
$\mathrm{Bh}_{\text {max }}(\mathrm{MGOe})$ & 4,56 & 4,94 & 5,07 \\
Density $\left(\mathrm{g} / \mathrm{cm}^{3}\right)$ & 4,74 & 4,78 & 4,79 \\
Gauss & 2100 & 1700 & 1640 \\
\hline \hline
\end{tabular}

atur maka semakin besar juga nilai $\mathrm{B}_{r}$ dan kuat medan (rapat fluk) magnet, temperatur $200^{\circ} \mathrm{C}$ menunjukan bahwa ini adalah temperatur efektif untuk temperatur burn compact pembuatan magnet bonded $\mathrm{NdFeB}$ dengan menggunakan serbuk magnet MQEP 16-7.

Pada eksperimen ini dilakukan variasi tekanan kompaksi green compact, sedangkan temperatur burn compact tetap yaitu pada temperatur $200^{\circ} \mathrm{C}$, tujuannya adalah untuk mencari tekanan kompaksi yang efektif untuk green compact. Nilai $\mathrm{B}_{r}$ terbesar diperoleh saat tekanan kompaksi green compact $25 \mathrm{~kg} / \mathrm{cm}^{2}$ yaitu $5,28 \mathrm{kG}$. Semakin besar tekanan kompaksi maka semakin kecil juga nilai $\mathrm{B}_{r}$ dan kuat medan (rapat fluk) magnet. Tekanan kompaksi $25 \mathrm{~kg} / \mathrm{cm}^{2}$ menunjukan bahwa ini adalah tekanan efektif untuk green compact dengan menggunakan serbuk magnet MQEP 16-7.

\section{SIMPULAN}

Dari eksperimen yang telah dilakukan dapat diketahui bahwa perlakuan optimal proses pembuatan magnet bonded NdFeB menggunakan serbuk magnet MQEP 16-7 dengan teknik kompaksi green compact diperoleh pada tekanan kompaksi $25 \mathrm{~kg} / \mathrm{cm}^{2}$ dan temperatur burn compact $200{ }^{\circ} \mathrm{C}$. Dari hasil karakterisasi sifat magnet pada perlakuan tersebut diperoleh nilai $\mathrm{B}_{r}$ sebesar 5,28 kG, nilai $\mathrm{H}_{c}$ sebesar 6,618 Koe, $\mathrm{Bh}_{\max }$ sebesar 4,56 MGOe dan kuat medan magnet sebesar 2100 Gauss.

\section{Ucapan Terima Kasih}

Pada kesempatan ini kami ingin menyampaikan ucapan terima kasih kepada Pusat Penelitian Elektronika dan Telekomunikasi (PPET - LIPI) yang telah memberikan kesempatan sehingga penelitian ini dapat terealisasi.
[1] Q. Wanzhong, Journal of Advanced Material Research, 841-846 (2011).

[2] M. Hamano, J. Alloys Compounds, 222, 8-12 (1995).
[3] J. Li, et al., Journal of Magnetism and Magnetic Materials, 299, 195-204 (2005). 